OPEN ACCESS

Edited by:

Qinghua He,

Southwest University, China

Reviewed by:

Hui Lei,

Hunan Agricultural University, China

Juan Yang,

Hainan Medical University, China

${ }^{*}$ Correspondence:

Lingyu Kong

365411020@qq.com

Specialty section:

This article was submitted to

Psychopathology,

a section of the journal

Frontiers in Psychiatry

Received: 07 December 2017

Accepted: 08 January 2018

Published: 23 January 2018

Citation:

Liu N, Liu S, Yu N, Peng Y, Wen Y,

Tang J and Kong L (2018)

Correlations among Psychological

Resilience, Self-Efficacy, and

Negative Emotion in Acute

Myocardial Infarction Patients after

Percutaneous Coronary Intervention.

Front. Psychiatry 9:1.

doi: 10.3389/fpsyt.2018.00001

\section{Correlations among Psychological Resilience, Self-Efficacy, and Negative Emotion in Acute Myocardial Infarction Patients after Percutaneous Coronary Intervention}

\author{
Neng Liu' ${ }^{1}$, Shaohui Liu' ${ }^{2}$, Nan Yu' ${ }^{1}$, Yunhua Peng ${ }^{1}$, Yumei Wen ${ }^{1}$, Jie Tang ${ }^{1}$ and Lingyu Kong ${ }^{3 *}$ \\ 'Department of Geriatric Cardiology, Xiangya Hospital, Central South University, Changsha, China, ${ }^{2}$ Health Management \\ Center, Xiangya Hospital, Central South University, Changsha, China, ${ }^{3}$ Department of Radiology, Xiangya Hospital, Central \\ South University, Changsha, China
}

Objective: We investigated the influencing factors of the psychological resilience and self-efficacy of acute myocardial infarction (AMI) patients after percutaneous coronary intervention $(\mathrm{PCl})$ and the relationships of psychological resilience and self-efficacy with negative emotion.

Methods: Eighty-eight participants were enrolled. Psychological resilience, self-efficacy, and negative emotion were assessed with the Psychological Resilience Scale, SelfEfficacy Scale, Zung Self-Rating Anxiety Scale (SAS), and Zung Self-Rating Depression Scale (SDS), respectively. Furthermore, the relationships of psychological resilience and self-efficacy with negative emotion were investigated.

Results: The average scores of psychological resilience, self-efficacy, anxiety, and depression were $70.08 \pm 13.26,21.56 \pm 9.66,53.68 \pm 13.10$, and $56.12 \pm 12.37$, respectively. The incidences of anxiety and depression were $23.90 \%(21 / 88)$ and $28.40 \%$ (25/88), respectively. The psychological resilience and self-efficacy scores of AMI patients after PCl varied significantly with age and economic status. SAS scores and SDS scores were significantly negatively correlated with psychological resilience and self-efficacy.

Conclusion: Negative emotions in AMl patients after $\mathrm{PCl}$ are closely related to psychological resilience and self-efficacy. Therefore, anxiety and depression could be alleviated by improving the psychological resilience and self-efficacy of patients undergoing $\mathrm{PCl}$, thus improving patients' quality of life.

Keywords: psychological resilience, self-efficacy, negative emotions, acute myocardial infarction, percutaneous coronary intervention

\section{INTRODUCTION}

In recent years, coronary heart disease has become one of the chronic diseases that pose serious threats to human health, and its incidence has been increasing year by year (1). One new patient is diagnosed with coronary heart disease every $25 \mathrm{~s}$ in the United States, and about $34 \%$ of patients die in the same year, equivalent to one death per minute (2). Psychological problems in patients with cardiovascular disease have attracted great attention (3). One study found that $19-66 \%$ of 
patients with acute myocardial infarction (AMI) develop anxiety or depression, which in turn increases the mortality of AMI patients (4).

As an important treatment for coronary heart disease, percutaneous coronary intervention (PCI) has a significant effect on improving myocardial ischemia caused by acute or persistent ischemia and hypoxia in coronary arteries (5-7). Since it is an invasive treatment, PCI is a serious stressful event for patients. Several studies have shown that PCI patients have serious psychological problems, including high levels of anxiety and depression, strong disease uncertainty, and low self-evaluation, which can affect the health of patients (8-11).

However, with the rise of positive psychology, the study of mental health problems in AMI patients after PCI is no longer confined to negative psychological factors, but has expanded to positive psychological factors. Psychological resilience and selfefficacy are two hot topics in this area.

Psychological resilience is the ability of individuals to maintain their healthy and orderly development in the face of various unfavorable factors (12-14). Good psychological resilience plays a positive role in promoting disease development and prognosis, can significantly slow the progression of the disease, reduce the body's inflammatory response to protect the damaged myocardium, and play a protective role in patients with myocardial infarction (15). Studies have shown that for patients with coronary heart disease, the prognosis is better when patients have higher levels of mental flexibility (16). Therefore, improving patients' psychological resilience can effectively promote their physical and mental health.

The concept of self-efficacy was proposed by Bandura in 1977 on the basis of the surgery-related efficacy expectations (17). Self-efficacy refers to the confidence or belief of an individual in his/her ability to overcome a difficult situation or accomplish a certain behavioral goal, and its main role is achieved through motivational, cognitive, selection, and emotional reaction processes. Studies have shown that the stronger patients' self-efficacy, the more confident they are in the face of adversity and the fight against their disease, and the better able they are to face the disease with a positive and healthy attitude (18-21).

The present study aimed to investigate the influencing factors of the psychological resilience and self-efficacy of AMI patients after PCI and analyze the relationships of psychological resilience, self-efficacy with negative emotion, which would provide a theoretical reference for clinicians to develop practical measures.

\section{MATERIALS AND METHODS}

\section{Participants}

Eighty-eight participants were recruited to participate in this study. All research protocols were explained to the participants, and they signed the written consent form approved by the local IRB (Xiangya Hospital of Central South University of Hunan Province, Changsha, China) before any examinations. Patients were randomly selected from the Department of Geriatric Cardiology of Xiangya Hospital, Central South University, Changsha, Hunan Province from March 2017 to November 2017. Inclusion criteria were as follows: age $\geq 18$ years; patients with AMI (defined by the presence of typical prolonged chest pain accompanied by serial changes on the ECG and an increase in cTnI above the upper normal range) (22); whether PCI was performed was based on the results of coronary angiography decisions. There were 74 males (84.1\%) and 14 females $(15.9 \%)$, aged $30-82(62.1 \pm 13.1)$ years.

\section{Procedures}

Participants were inpatients in the Department of Geriatric Cardiology of Xiangya Hospital. The questionnaire was issued on the third day after coronary stent implantation (the day of the coronary stent implantation was the first day). The respondents completed the questionnaire independently under the guidance of unified instruction, and the contents of the questionnaire were in accordance with their own actual situation and self-perception. For patients with special circumstances who could not fill out the forms by themselves, the researchers read the questionnaire out loud sentence by sentence and wrote the answers on behalf of the patients after the patients made their choices.

\section{Survey Scale}

\section{Self-compiled Questionnaire of General Situation}

The general situation questionnaire included age, sex, education, residence, average monthly family income, payment of medical expenses, other diseases or complications, the duration of coronary heart disease, the number of stent implantations, and the number of stents.

\section{Anxiety and Depression Scales}

The anxiety level of patients was evaluated by the Zung Self-Rating Anxiety Scale (SAS), consisting of 20 items. A score $\geq 50$ points indicates anxiety; the higher the score, the higher the degree of anxiety. The Cronbach's $\alpha$ coefficient of the scale is 0.887 and the content validity is 0.910 , while the internal consistency of the scale is good. The depression degree of patients was assessed by the Zung Self-Rating Depression Scale (SDS). The total score $\geq 50$ is classified as depression-positive. The higher the score, the higher the degree of depression. The Cronbach's $\alpha$ coefficient of the scale is 0.885 and the content validity is 0.826 , while the internal consistency of the scale is good $(23,24)$. These two scales can be used in hospitalized patients (25).

\section{The Connor-Davidson Resilience Scale}

The psychometric questionnaire designed by the American psychologists Connor and Davidson was used to evaluate resilience (26). The reliability and validity of the questionnaire are good, and the internal consistency is 0.91 . This questionnaire consists of 25 entries covering three dimensions: toughness (13 items), strength (8), and optimism (4). All entries use a 0-to-4 rating method, 0 meaning not at all 4 meaning almost always the case.

\section{Self-efficacy Scale}

To measure self-efficacy, we used the general self-efficacy scale (Chinese version) designed by Shi et al. (27), with internal consistency 0.889 , test-retest reliability 0.865 , and good reliability and validity. The scale involves 10 entries, including the individual's ability to solve problems, self-confidence to deal with 
things, achievement of goals, and so on. All entries use a 1-to-4 rating method, and the total score ranges from 10 to 40 points. Self-efficacy is classified into one of three levels according to the score: $31-40$ points is considered a high level, 20-30 an average level, and 10-19 a low level. A higher score indicates higher self-efficacy.

\section{Statistical Analysis}

All variables were described with number $(n)$, percentage (\%), mean $(\mathrm{M})$, SD, and range. Group differences of continuous variables were examined using the independent-samples $t$ test or oneway analysis of variance. Correlations among continuous variables were tested using Pearson's correlation analysis. Statistical analysis was executed by SPSS 22.0 software, and a two-tailed $p<0.05$ was viewed as statistically significant.

\section{RESULTS}

The average scores of psychological resilience, self-efficacy, anxiety, and depression were 70.08 $\pm 13.26,21.56 \pm 9.66,53.68 \pm 13.10$, and $56.12 \pm 12.37$ points, respectively. The incidences of anxiety and depression were $23.90 \%(21 / 88)$ and $28.40 \%$ (25/88), respectively (Table 1).

Self-Rating Anxiety Scale scores, SDS scores, psychological resilience scores, and self-efficacy scores of AMI patients after PCI varied significantly with age and average monthly income (Table 2).

Correlation analysis revealed that psychological resilience was significantly negatively correlated with SAS scores $(p<0.01$, $r=-0.854$; Figure 1) and SDS scores $(p<0.01, r=-0.869$; Figure 2). In addition, self-efficacy was significantly negatively correlated with SAS scores ( $p<0.01, r=-0.815$; Figure 3) and SDS scores $(p<0.01, r=-0.826$; Figure 4$)$.

\section{DISCUSSION}

In the present study, we recruited $88 \mathrm{AMI}$ patients after PCI to investigate the relationship of psychological resilience and selfefficacy with negative emotion. The results suggested that different ages and different average monthly incomes were the influencing factors of the psychological resilience and self-efficacy of AMI patients after PCI. Specifically, psychological resilience and selfefficacy were negatively correlated with SAS and SDS scores.

As a major source of stress response, AMI has great physiological and psychological impacts on patients, and after PCI, the treatment of AMI brings significant adverse reactions in patients, which will further increase the patients' psychological burden, potentially leading to PCI-related anxiety or depression. Gu et al.

TABLE 1 | Descriptive statistics for continuous variables.

\begin{tabular}{lcc}
\hline & Average scores (M $\pm \mathbf{S D})$ & Incidence (\%) \\
\hline Psychological resilience & $70.08 \pm 13.26$ & - \\
Self-efficacy & $21.56 \pm 9.66$ & - \\
Self-Rating Anxiety Scale & $53.68 \pm 13.10$ & $23.9 \%(21 / 88)$ \\
Self-Rating Depression Scale & $56.12 \pm 12.37$ & $28.4 \%(25 / 88)$
\end{tabular}

TABLE 2 | Demographic and clinical variables of participants in relation to psychological resilience and self-efficacy scores (scores, $\mathrm{M} \pm \mathrm{SD}$ ).

\begin{tabular}{|c|c|c|}
\hline Variable & $\begin{array}{l}\text { Psychological } \\
\text { resilience (M } \pm \mathrm{SD})\end{array}$ & $\begin{array}{l}\text { Self-efficacy } \\
\qquad(M \pm S D)\end{array}$ \\
\hline \multicolumn{3}{|l|}{ Gender } \\
\hline Male $(n=74)$ & $68.90 \pm 13.39$ & $20.57 \pm 8.64$ \\
\hline Female $(n=14)$ & $\begin{array}{c}76.25 \pm 12.31 \\
0.320\end{array}$ & $\begin{array}{c}26.75 \pm 14.36 \\
0.249\end{array}$ \\
\hline \multicolumn{3}{|l|}{ Age (in years) } \\
\hline$\geq 60(n=56)$ & $69.25 \pm 15.35$ & $20.06 \pm 10.30$ \\
\hline$<60(n=32)$ & $71.56 \pm 9.06$ & $24.22 \pm 8.27$ \\
\hline$p$ & $0.031^{*}$ & $0.026^{\star}$ \\
\hline \multicolumn{3}{|l|}{ Education } \\
\hline Primary school $(n=32)$ & $68.22 \pm 14.73$ & $23.0 \pm 9.24$ \\
\hline Junior high school $(n=17)$ & $70.40 \pm 6.42$ & $14.8 \pm 4.65$ \\
\hline Senior high school $(n=16)$ & $61.40 \pm 15.19$ & $19.0 \pm 13.28$ \\
\hline Junior college and above $(n=23)$ & $79.8 \pm 9.13$ & $27.17 \pm 7.68$ \\
\hline$p$ & 0.235 & 0.456 \\
\hline \multicolumn{3}{|l|}{ Residence } \\
\hline City $(n=39)$ & $74.00 \pm 12.88$ & $21.36 \pm 10.90$ \\
\hline Town $(n=10)$ & $65.00 \pm 23.0$ & $19.67 \pm 13.61$ \\
\hline Countryside $(n=39)$ & $67.54 \pm 10.86$ & $22.27 \pm 9.66$ \\
\hline$p$ & 0.268 & 0.834 \\
\hline \multicolumn{3}{|l|}{ Average monthly family income } \\
\hline$\leq 3,000(n=52)$ & $63.07 \pm 7.92$ & $18.80 \pm 9.34$ \\
\hline$>3,000(n=36)$ & $80.60 \pm 7.91$ & $25.7 \pm 9.02$ \\
\hline$p$ & $<0.001^{*}$ & $0.024^{*}$ \\
\hline \multicolumn{3}{|l|}{ Payment of medical expenses } \\
\hline Health insurance $(n=53)$ & $72.67 \pm 14.61$ & $20.86 \pm 10.59$ \\
\hline $\begin{array}{l}\text { Rural cooperative medical service } \\
(n=35)\end{array}$ & $66.20 \pm 10.44$ & $22.60 \pm 8.51$ \\
\hline$p$ & 0.240 & 0.671 \\
\hline \multicolumn{3}{|l|}{ Co-occurring diseases } \\
\hline None $(n=35)$ & $68.6 \pm 11.19$ & $18.90 \pm 9.27$ \\
\hline $1(n=42)$ & $70.42 \pm 16.22$ & $24.58 \pm 9.79$ \\
\hline$\geq 2(n=11)$ & $73.67 \pm 8.33$ & $18.33 \pm 10.02$ \\
\hline$p$ & 0.850 & 0.336 \\
\hline \multicolumn{3}{|l|}{ The number of stent implantations } \\
\hline $1(n=67)$ & $72.68 \pm 13.39$ & $23.26 \pm 9.24$ \\
\hline$\geq 2(n=21)$ & $61.83 \pm 9.56$ & $16.17 \pm 9.74$ \\
\hline$p$ & 0.080 & 0.119 \\
\hline
\end{tabular}

(10) found that negative emotions in patients with AMI peaked on the first day after PCI. The findings of the present study showed that the incidence of SAS in patients with PCI was $23.9 \%(21 / 88)$ and that of SDS was $28.4 \%(25 / 88)$, consistent with the findings of Polikandrioti et al. (28) and Suzuki et al. (29). Although the mechanism of the relationship between negative emotions and cardiovascular disease is not yet clear, anxiety and depression play an important role in the occurrence, development, rehabilitation, and prognosis of coronary heart disease (30), and they are extremely unfavorable to patients' rehabilitation and prognosis. Some scholars note that as a positive psychology model, psychological resilience plays an important role in eliminating these negative emotions and in the overall care of cardiovascular patients (31).

The study showed that patients after PCI had an average resilience score of $70.08 \pm 13.26$ points, lower than that of the general population $(80.4 \pm 12.8)(26)$, indicating a low level of psychological resilience in patients undergoing PCI. The reason might be that some patients have anxiety, depression, fear, and 


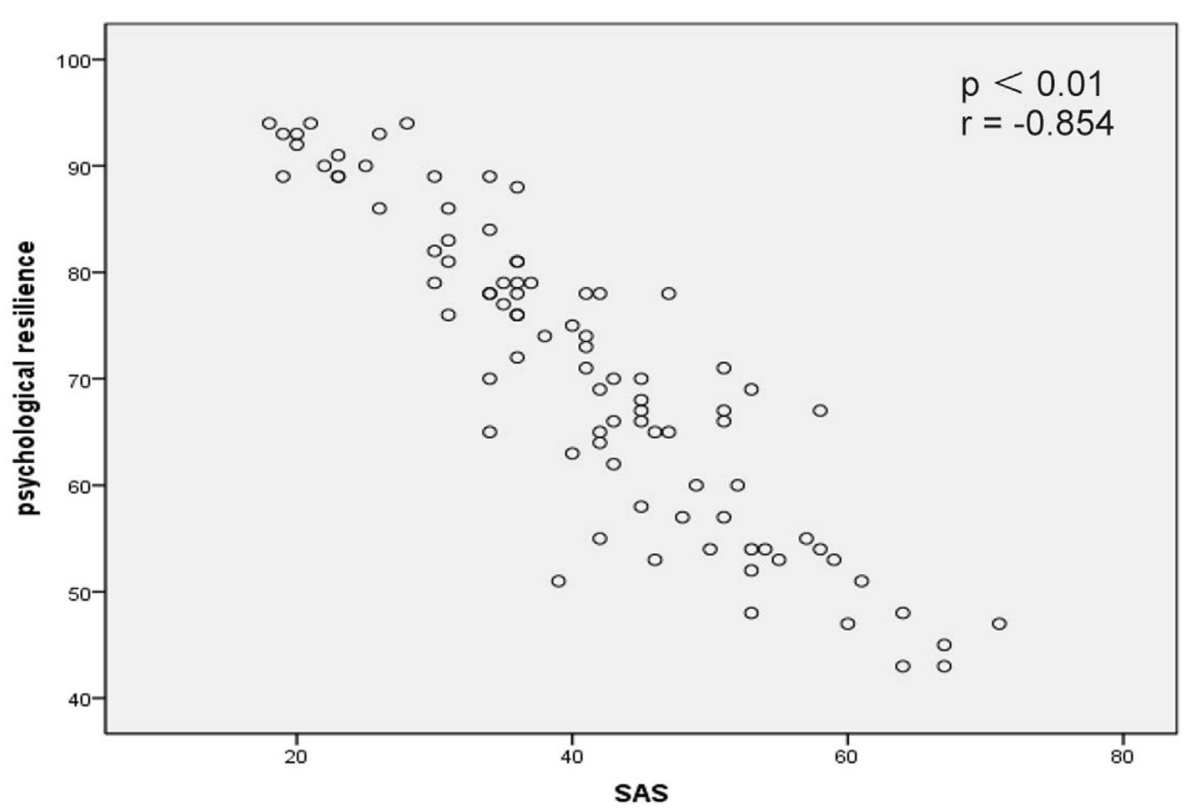

FIGURE 1 | Correlation map between psychological resilience within Self-Rating Anxiety Scale (SAS) scores in acute myocardial infarction patients after percutaneous coronary intervention $(p<0.01, r=-0.854)$.

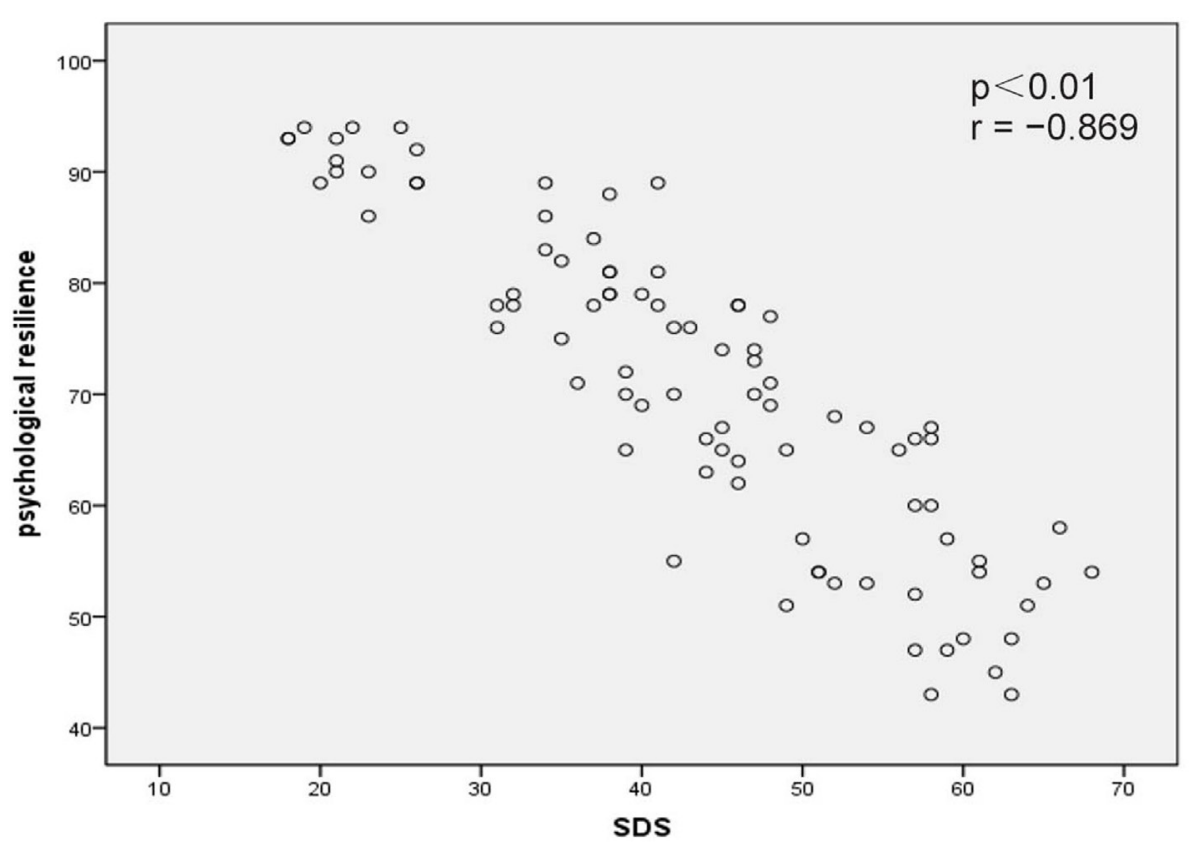

FIGURE 2 | Correlation map between psychological resilience within Self-Rating Depression Scale (SDS) scores in acute myocardial infarction patients after percutaneous coronary intervention $(p<0.01, r=-0.869)$.

other psychological problems, thus affecting their adaptation to the disease, resulting in poor psychological resilience. A single intervention study with 226 breast cancer patients found that patients with higher psychological resilience could have a 3-to-5-year increase in survival (32). Lossnitzer et al. (33) also confirmed that the relationship between psychological resilience and the patient's own psychological variables was close, but found that it was not closely related to the patient's disease severity, which corroborates our finding that there was no significant correlation between psychological resilience scores and the number 


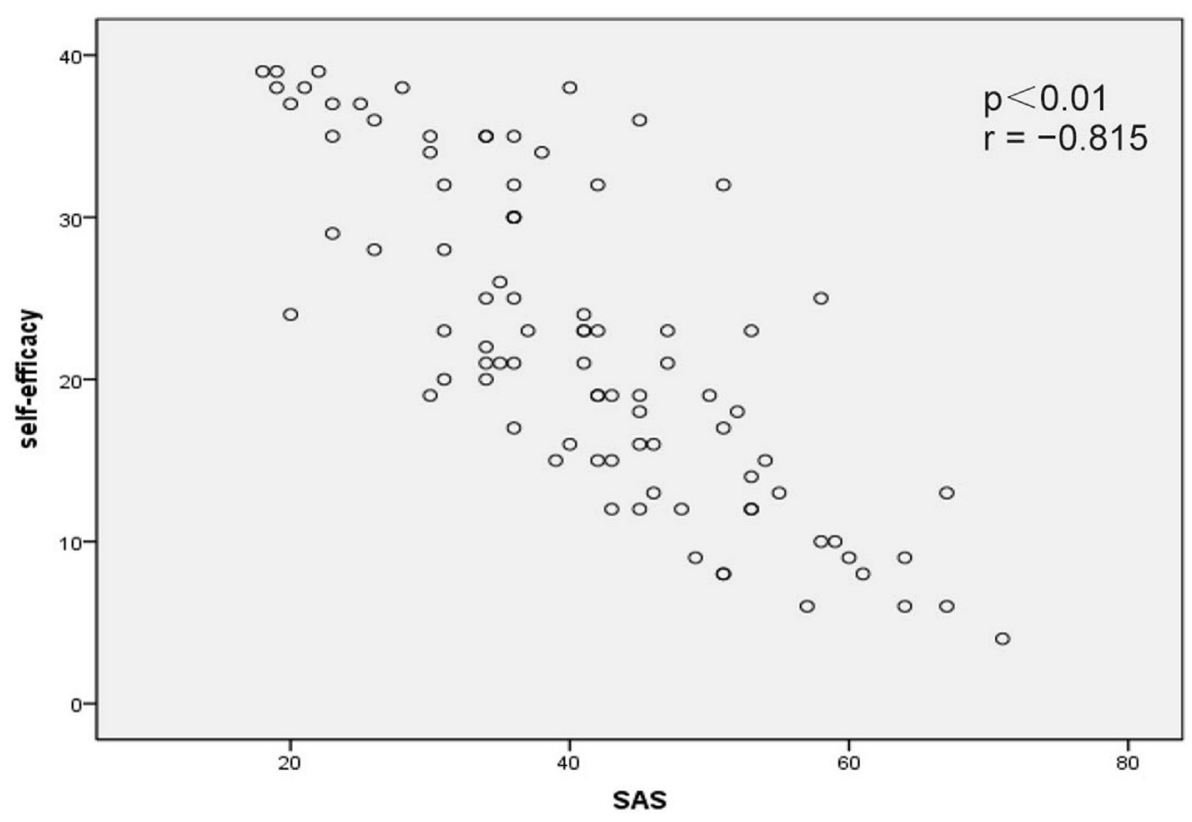

FIGURE 3 | Correlation map between self-efficacy within Self-Rating Anxiety Scale (SAS) scores in acute myocardial infarction patients after percutaneous coronary intervention $(p<0.01, r=-0.815)$.

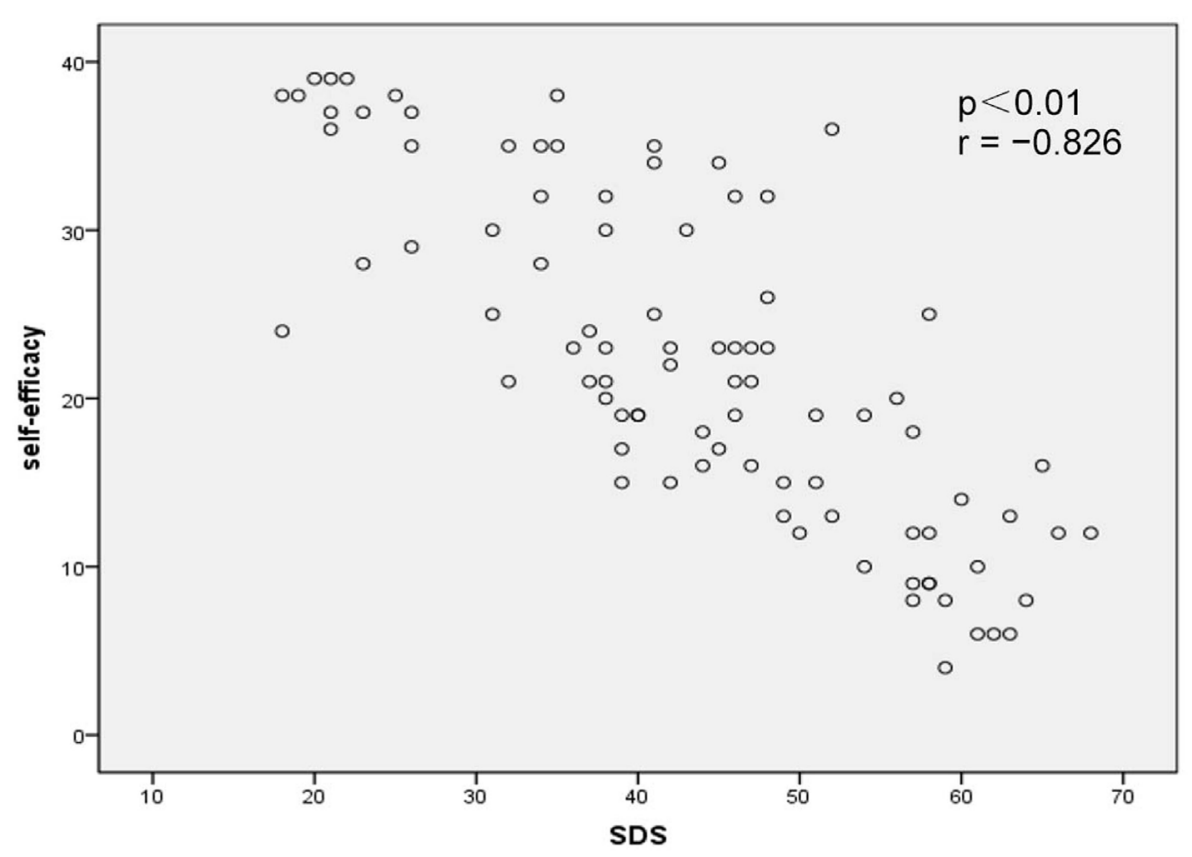

FIGURE 4 | Correlation map between self-efficacy within Self-Rating Depression Scale (SDS) scores in acute myocardial infarction patients after percutaneous coronary intervention $(p<0.01, r=-0.826)$.

of stents used. Therefore, it is necessary for health care workers to communicate with patients and their families and provide support and assistance to patients through concern, affection, and psychological counseling in order to allow patients to share their pain and fear, relieve their pressure, help them understand themselves better, and improve their psychological resilience mechanism against diseases.

Self-efficacy, the confidence and belief of individuals in their ability to effectively implement own actions or overcome difficulties, is the core of self-management. Studies have shown that 
self-efficacy is conducive to the establishment of a healthy and positive attitude in patients, which helps to improve the patients' confidence in the treatment of their disease (34). In this study, the average self-efficacy score of patients after PCI was $21.56 \pm 9.66$ points, suggesting that patients have low self-efficacy after PCI. This might be because under the influence of diseases and serious adverse reactions, the psychological moods of patients change greatly, so that patients in such an environment may lack confidence. Health care workers should attach importance to cultivating and improving patients' general sense of self-efficacy; changing patients' attitudes and perceptions of discomfort caused by PCI through various means, such as developing selfcare programs and strengthening health education for patients; enhancing patients' confidence in treatment; and guiding patients to be active in dealing with the adverse effects of disease and PCI in order to maintain a good state of mind during their treatment, thereby improving their quality of life.

This study found significant differences in psychological resilience and self-efficacy scores depending on age and economic status. The psychological resilience and self-efficacy scores of elderly patients were lower than those of middle-aged and young patients, which may be related to their poor psychological endurance and psychological adaptability $(35,36)$. Self-efficacy also varied with economic status, which may be because patients with poor economic status have heavy financial burdens, which leads to greater psychological stress; patients with poor economic status also generally have poor psychological endurance and are prone to anxiety, depression, and other symptoms during treatment.

Self-Rating Anxiety Scale scores and SDS scores in our study were negatively correlated with psychological resilience and selfefficacy $(p<0.05)$, suggesting that there was a close relationship between negative emotions and psychological resilience and self-efficacy in patients after PCI, which was consistent with

\section{REFERENCES}

1. Fuster V, Kelly BB; Institute of Medicine (US) Committee on Preventing the Global Epidemic of Cardiovascular Disease. Meeting the Challenges in Developing Countries, Promoting Cardiovascular Health in the Developing World: A Critical Challenge to Achieve Global Health. Washington, DC: National Academies Press (US) (2010). The National Academies Collection: Reports Funded by National Institutes of Health.

2. Lloyd-Jones D, Adams R, Carnethon M, De Simone G, Ferguson TB, Flegal K. Heart disease and stroke statistics - 2009 update: a report from the American Heart Association Statistics Committee and Stroke Statistics Subcommittee. Circulation(2009)119(3):480-6.doi:10.1161/CIRCULATIONAHA.108.191259

3. Watkins LL, Koch GG, Sherwood A, Blumenthal JA, Davidson JR, O'Connor C. Association of anxiety and depression with all-cause mortality in individuals with coronary heart disease. JAm Heart Assoc (2013) 2(2):e000068. doi:10.1161/JAHA.112.000068

4. Doering LV, Moser DK, Riegel B, McKinley S, Davidson P, Baker H, et al. Persistent comorbid symptoms of depression and anxiety predict mortality in heart disease. Im J Cardiol (2010) 145(2):188-92. doi:10.1016/j.ijcard.2009.05

5. Aazami S, Jaafarpour M, Mozafari M. Exploring expectations and needs of patients undergoing angioplasty. J Vasc Nurs (2016) 34(3):93-9. doi:10.1016/j. jvn.2016.04.003

6. Tang L, Zhou SH, Hu XQ, Fang ZF, Shen XQ. Effect of delayed vs immediate stent implantation on myocardial perfusion and cardiac function in patients with ST-segment elevation myocardial infarction undergoing primary studies by Rigby et al. (37), Carvalho et al. (38), and others. Higher anxiety and depression are often accompanied by low psychological resilience and self-efficacy. Patients with higher self-efficacy have stronger confidence in their treatment, higher psychological resilience, lower risk of stress disorder, and lower anxiety or depression. This suggests that clinicians and patients' families should try to improve patients' self-efficacy and enhance patients' confidence in treatment in order to improve the patients' psychological resilience and improve their mood.

In sum, the negative emotions of AMI patients after PCI were closely related to psychological resilience and self-efficacy. Steps should be taken to help patients with older age and poor financial status to improve their psychological resilience and self-efficacy as well as reduce their anxiety and depression.

A few limitations of this study should be noted. First, the sample size was relatively small. Second, this was a cross-sectional and correlational study, which limits the ability to infer causality. Third, further longitudinal studies should be conducted to replicate and expand on the findings of this study.

\section{ETHICS STATEMENT}

All participants were aware of the purpose of the study and signed an informed consent before the study. All research protocols were explained to the participants, and they signed a written consent form approved by the local IRB (Xiangya Hospital of Central South University of Hunan Province, Changsha, China).

\section{AUTHOR CONTRIBUTIONS}

NL, SL, and LK conceived and designed the experiments. NY, YP, YW, and JT conducted the experiments and collected data. NL and LK analyzed the results and wrote the main manuscript text. All authors reviewed the manuscript.

percutaneous intervention with thrombus aspiration. Can J Cardiol (2011) 27(5):541-7. doi:10.1016/j.cjca.2011.03.001

7. Chen C, Huang Y, Zhou S, Fang Z. Influencial factors for in-hospital patients with ST segment elevation myocardial infarction after emergency percutaneous coronary intervention. Zhong Nan Da Xue Xue Bao Yi Xue Ban (2016) 41(11):1186-92. doi:10.11817/j.issn.1672-7347.2016.11.012

8. Bulhões MKM, de Andrade TM. What do patients think about while waiting for myocardial revascularization. Crit Pathw Cardiol (2013) 12(4):188-91. doi:10.1097/HPC.0b013e3182a2c801

9. de Jager TAJ, Dulfer K, Radhoe S, Bergmann MJ, Daemen J, van Domburg RT, et al. Predictive value of depression and anxiety for long-term mortality: differences in outcome between acute coronary syndrome and stable angina pectoris. Int J Cardiol (2018) 250:43-8. doi:10.1016/j.ijcard. 2017.10.005

10. Gu G, Zhou Y, Zhang Y, Cui W. Increased prevalence of anxiety and depression symptoms in patients with coronary artery disease before and after percutaneous coronary intervention treatment. BMC Psychiatry (2016) 16:259. doi:10.1186/s12888-016-0972-9

11. Du J,Zhang D, Yin Y,ZhangX, Li J, Liu D, et al. The personality and psychological stress predict major adverse cardiovascular events in patients with coronary heart disease after percutaneous coronary intervention for five years. Medicine (Baltimore) (2016) 95(15):e3364. doi:10.1097/MD.0000000000003364

12. Tusaie K, Dyer J. Resilience: a historical review of the construct. Holist Nurs Pract (2004) 18(1):3-8; quiz 9-10. doi:10.1097/00004650-20040100000002 
13. Shakespeare-Finch J, Gow K, Smith S. Personality, coping and posttraumatic growth in emergency ambulance personnel. Traumatology (2005) 11(4):325. doi:10.1177/153476560501100410

14. Ebersöhn L, Eloff I, Finestone M, Grobler A, Moen M. Telling stories and adding scores: measuring resilience in young children affected by maternal HIV and AIDS. Afr J AIDS Res (2015) 14(3):219-27. doi:10.2989/16085906 .2015 .1052822

15. Arrebola-Moreno AL, Garcia-Retamero R, Catena A, Marfil-Álvarez R, Melgares-Moreno R, Ramírez-Hernández JA. On the protective effect of resilience in patients with acute coronary syndrome. Int J Clin Health Psychol (2014) 14(2):111-9. doi:10.1016/S1697-2600(14)70044-4

16. de Lemos CM, Moraes DW, Pellanda LC. Resilience in patients with ischemic heart disease. Arq Bras Cardiol (2016) 106(2):130-5. doi:10.5935/abc.20160012

17. Bandura A. Self-efficacy: toward a unifying theory of behavioral change. Psychol Rev (1977) 84:191-215. doi:10.1037/0033-295X.84.2.191

18. Baruth M, Wilcox S, Schoffman DE, Becofsky K. Factors associated with disability in a sample of adults with arthritis. Disabil Health J (2013) 6(4):377-84. doi:10.1016/j.dhjo.2013.04.008

19. Hughes AJ, Beier M, Hartoonian N, Turner AP, Amtmann D, Ehde DM. Self-efficacy as a longitudinal predictor of perceived cognitive impairment in individuals with multiple sclerosis. Arch Phys Med Rehabil (2015) 96(5):913-9. doi:10.1016/j.apmr.2015.01.008

20. Náfrádi L, Nakamoto K, Schulz PJ. Is patient empowerment the key to promote adherence? A systematic review of the relationship between self-efficacy, health locus of control and medication adherence. PLoS One (2017) 12(10):e0186458. doi:10.1371/journal.pone.0186458

21. Sangruangake M, Jirapornkul C, Hurst C. Psychometric properties of diabetes management self-efficacy in thai type 2 diabetes mellitus patients: a multicenter study. Int J Endocrinol (2017) 2017:2503156. doi:10.1155/2017/2503156

22. Pan W, Yu J, Shi R, Yan L, Yang T, Li Y, et al. Elevation of ceramide and activation of secretory acid sphingomyelinase in patients with acute coronary syndromes. Coron Artery Dis (2014) 25(3):230-5. doi:10.1097/MCA.0000000000000079

23. Pihl E, Jacobsson A, Fridlund B, Strömberg A, Mårtensson J. Depression and health-related quality of life in elderly patients suffering from heart failure and their spouses: a comparative study. Eur J Heart Fail (2005) 7:583-9. doi:10.1016/j.ejheart.2004.07.016

24. Kourea K, Parissis JT, Farmakis D, Paraskevaidis I, Panou F, Filippatos G, et al. Effects of darbepoetin-alpha on quality of life and emotional stress in anemic patients with chronic heart failure. Eur J Cardiovasc Prev Rehabil (2008) 15:365-9. doi:10.1097/HJR.0b013e3282f849d0

25. ParissisJT,Nikolaou M, FarmakisD, Bistola V, ParaskevaidisIA, AdamopoulosS. Clinical and prognostic implications of selfrating depression scales and plasma B-type natriuretic peptide in hospitalised patients with chronic heart failure. Heart (2008) 94:585-9. doi:10.1136/hrt.2007.117390

26. Connor KM, Davidson JR. Development of a new resilience scale: the ConnorDavidson Resilience Scale (CD-RISC). Depress Anxiety (2003) 18(2):76-82. doi:10.1002/da.10113

27. Shi RC, Meng AF, Zhou WL, Yu XY, Huang XE, Ji AJ, et al. Effects of home nursing intervention on the quality of life of patients with nasopharyngeal carcinoma after radiotherapy and chemotherapy. Asian Pac J Cancer Prev (2015) 16(16):7117-21. doi:10.7314/APJCP.2015.16.16.7117
28. Polikandrioti M, Goudevenos J, Michalis LK, Koutelekos J, Kyristi H, Tzialas $\mathrm{D}$, et al. Factors associated with depression and anxiety of hospitalized patients with heart failure. Hellenic J Cardiol (2015) 56(1):26-35.

29. Suzuki T, Shiga T, Kuwahara K, Kobayashi S, Suzuki S, Nishimura K, et al. Impact of clustered depression and anxiety on mortality and rehospitalization in patients with heart failure. J Cardiol (2014) 64(6):456-62. doi:10.1016/j. jjcc.2014.02.031

30. Tully PJ, Cosh SM, Baumeister H. The anxious heart in whose mind? A systematic review and meta-regression of factors associated with anxiety disorder diagnosis, treatment and morbidity risk in coronary heart disease. J Psychosom Res (2014) 77:439-48. doi:10.1016/j.jpsychores.2014.10.001

31. Garnefski N, Kraaij V, Schroevers MJ, Aarnink J, van der Heijden DJ, van Es SM, et al. Cognitive coping and goal adjustment after first-time myocardial infarction: relationships with symptoms of depression. Behav Med (2009) 35(3):79-86. doi:10.1080/08964280903232068

32. Ye ZJ, Qiu HZ, Liang MZ, Liu ML, Li PF, Chen P. Effect of a mentor-based, supportive-expressive program, Be Resilient to Breast Cancer, on survival in metastatic breast cancer: a randomised, controlled intervention trial. $\mathrm{Br}$ J Cancer (2017) 117(10):1486-94. doi:10.1038/bjc.2017.325

33. Lossnitzer N, Wagner E, Wild B, Frankenstein L, Rosendahl J, Leppert K, et al. Resilience in chronic heart failure. Dtsch Med Wochenschr (2014) 139(12):580-4. doi:10.1055/s-0034-1369862

34. Zhou Y, Liao J, Feng F, Ji M, Zhao C, Wang X. Effects of a nurse-led phone follow-up education program based on the self-efficacy among patients with cardiovascular disease. J Cardiovasc Nurs (2017) 33(1):E15-23. doi:10.1097/ JCN.0000000000000414

35. Bergh C, Udumyan R, Fall K, Almroth H, Montgomery S. Stress resilience and physical fitness in adolescence and risk of coronary heart disease in middle age. Heart (2015) 101(8):623-9. doi:10.1136/heartjnl-2014-306703

36. Scult M, Haime V, Jacquart J, Takahashi J, Moscowitz B, Webster A, et al. A healthy aging program for older adults: effects on self-efficacy and morale. $A d v$ Mind Body Med (2015) 29(1):26-33.

37. Rigby SA, Thornton EW, Young CA. A randomized group intervention trial to enhance mood and self-efficacy in people with multiple sclerosis. Br J Health Psychol (2008) 13:619-31. doi:10.1348/135910707X241505

38. Carvalho IG, Bertolli ED, Paiva L, Rossi LA, Dantas RA, Pompeo DA. Anxiety, depression, resilience and self-esteem in individuals with cardiovascular diseases. Rev Lat Am Enfermagem (2016) 24:e2836. doi:10.1590/ $1518-8345.1405 .2836$

Conflict of Interest Statement: The authors declare that the research was conducted in the absence of any commercial or financial relationships that could be construed as a potential conflict of interest.

Copyright $\odot 2018$ Liu, Liu, Yu, Peng, Wen, Tang and Kong. This is an open-access article distributed under the terms of the Creative Commons Attribution License (CC BY). The use, distribution or reproduction in other forums is permitted, provided the original author(s) or licensor are credited and that the original publication in this journal is cited, in accordance with accepted academic practice. No use, distribution or reproduction is permitted which does not comply with these terms. 